\title{
SJoP
}

\section{Inside the hos(t)pital}

\section{BEN HARRISON}

The Scottish Journal of Performance

Volume 5, Issue 1; April 2018

ISSN: 2054-1953 (Print) / ISSN: 2054-1961 (Online)

Publication details: http://www.scottishjournalofperformance.org

To cite this article: Harrison, B., 2018. Inside the hos(t)pital. Scottish Journal of Performance, 5(1): pp.119-134.

To link to this article: http://doi.org/10.14439/sjop.2018.0501.13

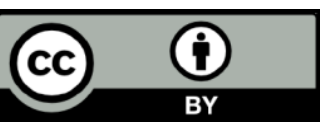

This work is licensed under a Creative Commons

Attribution 4.0 International License. See

http://creativecommons.org/licenses/by/4.0/ for details. 


\title{
Inside the hos(t)pital
}

\author{
BEN HARRISON
}

DOI: $10.14439 /$ sjop.2018.0501.13

Publication date: 6 April 2018

\section{Prologue}

Grid Iron is a theatre company based in Edinburgh which, since its corporation in 1995, swiftly gained a national and international reputation for site-based, site-suggestive and site-generic work. The author of this paper joined the company as Co-Artistic Director and has directed the majority of its productions. Highlights in a 21-year trajectory with the company include: The Bloody Chamber by Angela Carter staged in the then abandoned Mary King's Close (1997-8); Gargantua by Ben Harrison, based on the novel by Rabelais and staged in the abandoned vaults of the City Library and an old bank (which the company named the Underbelly, 1998); Decky Does A Bronco by Douglas Maxwell staged in children's swing parks (2000-2010); Those Eyes, That Mouth staged in an abandoned series of New Town apartments and then again in the former security headquarters of the Syrian Secret Police in Beirut (2003-5); Roam by Ben Harrison, staged in the airside and landside areas of Edinburgh International Airport (2006); and Crude by Ben Harrison, staged in Shed 31 at Dundee Ports, a vast industrial shed alongside three oil rigs berthed in the Tay River. Since the author joined Grid Iron, the company has won 29 awards across all aspects of its work. He has also made site work as a freelance director all over the world, and most notably with the Almeida Theatre in London and Muztheater in the Netherlands.

'Just remember it's our swing park!', 12-year-old girl, Portree Swing Park, Isle of Skye, April 2000. 
'In Lebanon, we prefer our theatres to be theatres and our hospitals to be hospitals'. Issam Bou Khaled, Alexandria, Egypt, December 2003.

'This is a wicked film'. Nine-year-old audience member, Caledonian Road, promenade site-based production, Almeida Theatre, 2002.

\section{Scene One}

$A$ Host $^{1}$ and a Guest meet in a location.

Host: So you want to come to do a show in my space. Why would you want to do it here? Wouldn't you be better off in a theatre? That's what they're for. Can't see what you would want with this dusty old place...

Guest: Well, the subject matter of the play really suits your space. That's what we do as a company, we try to create a dance, a conversation between the content of the piece and the architecture and feel of the site we choose. Sometimes one leads, sometimes the other. For instance, in 2006 I wrote and directed a piece called Roam (Harrison, 2006), which was inspired by a philosophical text by Michel Serres called Angels: A modern myth (2000). The text is constructed as a dialogue between two friends. $\mathrm{He}$ is a representative of an airline who has to fly around the world for his work. She is a doctor based in the airport. Together they muse on the travellers they see, characterising them as contemporary angels, as they carry messages across the globe. That concept really needed an airport to make it work in its fullest expression. Once we persuaded Edinburgh Airport to host it however, the particular architecture of that space began to construct the dramaturgy.

Host: You'll need to translate some of that into English... 
what's dramaturgy?

Guest: Well...

Host: I can't believe the airport hosted you! Were they not worried about security?

Guest: Dramaturgy... we'll need to discuss that over several glasses of wine! But for now, in terms of the airport, there were many factors that made it possible. The most important aspect was the timing. It was far enough away from 9/11, being staged in 2006, and it was just before the socalled liquid bomb plot. It was also the inaugural year of the National Theatre of Scotland, and the British Airports Authority (BAA) wanted to have a good bit of PR as the expansion of the airport site was proving controversial with local residents and with the environmental lobby. On a personal level, the terminal manager had been a theatre producer on the Fringe (when she was a student at Edinburgh University), so she had a bit of a handle on what we were about. That's by no means the case always. We recently made an enquiry about a site for our 2016 show Crude (Harrison, 2016) about the oil industry (see Fisher, 2016). The person on the other end of the line for an industrial lettings company didn't know what theatre was. He hadn't heard of it as a concept. It was eventually explained to him as like stand-up comedy (which he had heard of) but with more people!

In terms of security, all the members of the team were background-checked, we all had official security passes, and the audience all had to bring their passports to gain entry to the terminal.

Host: If you came and did your show here, my manager 
would want to read the script, to check that you're not implying anything negative about our business.

Guest: Of course. Most (but not all) hosts ask to read the script. And of course, we are careful not to offend those who are hosting us. We didn't make much of a feature of the environmental impact of air travel in Roam, because that was obviously something BAA wouldn't like. It would be the equivalent of serving a roasted hog at a dinner party for Muslim vegans. In the end, we made a very small comment in that one of the characters held up a taxi driver sign with ' $\mathrm{CO}_{2}$ ' written on it. We hid it in a crowd of other 'taxi drivers' with signs like 'God' and 'The End of Time'. In fact, the airport did censor one thing, which was the code for a suspicious abandoned bag. Ironically, I wouldn't have known the code unless someone had told me about it during my research at the airport. So, we just changed the number and it was fine.

Host: I'm not being funny, but you guys have your heads in the clouds, don't you? I mean you're just making mad stuff up, stories, whereas we're trying to run a business in the real world. Don't you just end up rubbing people up the wrong way?

Guest: Thanks for your direct question! Most people think that theatre people are a bit away with the fairies, yes, I think that's true. But what we do is go in and be more prepared than the hosts are. We have already done the risk assessments, the fire protocol, evacuation procedures, radio communication protocol, and all the myriad aspects of making a site-based promenade performance run smoothly in a multi-functioning space, whose lowest priority would be the show itself. In fact, in my experience, if the staff of a location haven't been won over in the early stages, they normally will be once the actors arrive for the first day of technical rehearsals. The actors bring glamour to the 
workplace. And we only work with actors who are openhearted, curious about the world, resilient, and courteous human beings. One loud-mouthed actor, confirming the biases of the hosts, can undo months of careful preparation.

Host: You can't make much money at this. I mean there's not going to be much space for the seats.

Guest: Well, we wouldn't actually be using seats for a project of this nature. The audience will walk around, following the action.

Host: But do you make any money at this?

Guest: We make enough to cover our costs. But no, we certainly don't make a profit!

Host: I still think you've got your head in the clouds. But anyway, I'll give you the guided tour. I can't promise anything mind, it'll be down to the higher-ups.

Guest: That would be great, thank you.

Host: There are some rooms we won't be able to go in because they're being used. I'll see if we can just pop our heads around the door of the main room though if that's being used. It would be good for you to see that.

Guest: Great, that's very kind thank you.

The Host and the Guest begin to walk around the building, along corridors, up stairs, into rooms, and down into the basement. 
Host: Don't worry about these walls here. We're getting the plasterers in. It'll be all fixed up by the time you guys get here.

Guest: Well, actually, that quality of these walls is one of the aspects of your building that really attracted me. It gives a real sense of the building's history-see those fragments of wallpaper and peeling paint? That kind of thing is very inspiring for us, for the actors, and for the audience. One of the characters in the piece has inhabited the building for a very long time; I'd probably stage one of her key scenes with that wall as a backdrop.

Host: Really? How odd. OK, well, I'll check about the building works schedule. We might be able to work around you. Just this stairwell now and a balcony area at the top and you'll have seen everything.

Guest: Thank you so much for your time. It's great to see all these hidden spaces. The building is just perfect for the piece. It far exceeds my expectations already.

\section{Scene Two}

The Host and the Guest have met up in a pub a couple of days after the opening night of the show. The Host is a little bit tipsy and gushing about the experience.

Host: I really liked how you made me see the place I work in in a new way. I mean, I walk down that corridor every day, but I had no idea about all those messages the builders had left up there, high up towards the ceiling. And, then, when we walked back down it, and it was all red, and you'd changed all the signage. It took me a good couple of minutes to realise it was the same corridor. 
Guest: Thanks, it was a lot of work and involved a lot of people working at speed to make that transformation, but I'm glad it worked for you.

Host: And then that dark room where I thought I was next to a speaker and then, when the lights went on, I realised there was actually an actor behind the grille! I nearly jumped out of my skin!

Guest: Thank you, that really means a lot. We do really try to investigate the site thoroughly and figure out its unique possibilities. Even now, sitting in this pub, my brain is fizzing with how one might use the bar, that door, that large table... how one could override the lighting to create the right effects for the action. The actors should be as familiar with it as their own bedroom, as familiar as I am with this bar we are sitting in. I'm a regular here. They really need to inhabit the space and not do anything that could be done in the more neutral space of a theatre stage. We always say things to actors like have you noticed the window, the light socket, the tap? What is your character's attitude to the staircase, the wooden knots in the floor, that trailing cable, the temperature, the light falling through the window, and so on?

Host: But you really didn't have much time in the space to prepare.

Guest: Sometimes that's a good thing. It's a mindset, more than necessarily having to live in the space. You can work quite quickly. In fact, sometimes you can spend too long in the space and then the actor starts doing the thing that isn't obvious, because good actors are naturally inventive beings and can get bored quite quickly. You need to do both the obvious and the extraordinary. For example, in Roam, the first location was the check-in area, so, of course we had to 
have characters staffing the desks, and other characters checking in. But then, later, we did the extraordinary by changing the departure destinations on the monitors to Beirut, Kigali and Sarajevo, staffing the desk with an Arab actor dressed in a militia uniform, having Scottish characters as refugees trying to flee a civil war-ravaged Scotland. But you have to do the obvious thing first.

Host: I felt involved. I felt like I was really in it. And it was a lot funnier than I thought it would be, the jokes you made with the audience, like when you turned those guys into filing cabinets. We had a much stronger role than I thought we would have, like we were actors too.

Guest: That's key I think. In fact, in quite a profound way, as soon as you become an audience member for the piece our roles reverse. I am the host, since I am in control of the fiction, the code, the flow through the building and the casting of you as an audience member. I have a duty of care. In a sense, you are in my hostpital... the building is transformed into a fictionalised version of itself, rooted in its own reality, but transformed into something other. It's my space now that I invite you into, even though you invited me in, in the first instance. But I will limit what I will ask you to do because you are encountering the fiction for the first time, in the moment. You haven't had the luxury of rehearsals, obviously.

Host: I did feel looked after, I felt safe that you knew where I was meant to be. I felt like the cast were ahead of me, showing me the way. I knew I had to do things in the show, but I didn't feel panicked. Just a bit excited that we were going into the unknown, but somehow, I trusted the actors to look after me.

Guest: Casting the audience is a huge part of that. When we 
did the show in the airport, we cast the audience as air passengers-who else could they be? For a show based on the writings of Charles Bukowski, Barflies, which we staged in our local pub, a bit like this one, we cast the audience as bar regulars and bought them a drink. In the show Decky Does A Bronco (Maxwell, 2001) which we staged in children's playgrounds across the UK and Ireland, we cast the audience as children by seating them in low stools in a circle (which lowered their eyeline) around a scaled up set of swings, which made the adult actors look smaller and made the audience feel smaller too. We once did a show, Those Eyes, That Mouth (Harrison \& Grid Iron, 2005), which was about a woman who had shut herself away from the world, which somewhat begged the question as to what the audience were doing there. So, we made them into the paranoid projections of her deep fear of the Others; most of the time, she didn't acknowledge our presence, but in the depths of her paranoid attacks she would suddenly stare, startled, at us. Years ago, in the first site piece I made for Grid Iron, an adaptation of Angela Carter's The Bloody Chamber (Carter, 1979) which we staged in Mary King's Close in Edinburgh, we needed to create the illusion of a library. We were in a narrow vault and there was no room to fit a library as well as the audience in. So, we cast the audience as the library shelves with the lead actor stroking their noses as if they were the spines of the books. In our follow-up show Gargantua (Harrison, 1998), which we created in a space that I named the Underbelly, in a series of vaults and chambers between Victoria Street and the Cowgate in Edinburgh, we used the audience as filing cabinets, filing paper in between their armpits and chests and then more daringly between their legs. We developed the idea of the hotspot in the audience, that is zeroing in on the person that is having the most fun and engagement and is therefore the most likely to be up for playing a more active role. In Gargantua, we picked two people to be the filing cabinets, and then in subsequent scenes kept building up a more a more flirtatious interaction with them, from glances to casual touching to the fifth scene where two 
actors had wrestled them to the floor and were licking their faces. Not something we would have attempted in the first scene!

You have to build up trust and even an erotic charge steadily and carefully to reach these moments of surprising intimacy. And you have to be a good host from the beginning. At the entrance to the site, typically Judith Doherty, the producer and co-artistic director of Grid Iron, will do an orientation and health and safety briefing for the audience at the end of which she wishes them good luck. This normally gets a laugh and just the right amount of nervous anticipation.

Host: I like the idea of a hostpital. I guess a hospital does have all kinds of rules and mysteries that the patient doesn't know. Perhaps doesn't want to know.

Guest: It's not an exact term because it is medicalised, and in a way, our kind of site-based work would be more erotic, sensual and funnier than a hospital would be. But I like it, because it absolutely centralises the idea of the host and the notion of care. Sometimes artists can get this so wrong. I once saw a promenade show about the Holocaust, where we were treated as prisoners and were shoved around and barked at-deeply unpleasant, especially as the actors playing soldiers were getting into their roles with the wrong kind of relish. At another show, the conceit of the piece was that we were escaping a zombie attack on Edinburgh and being protected (but also screened) by, again, soldiers. One of them was getting far too into his role, shoved over and swore at my partner, who went over on her heel and nearly broke her ankle. Not looking after the audience. Being terrible hosts in fact.

Host: It sounds like there's almost an unwritten contract? 
Guest: Yes, there is, although sometimes it can be written. One of the most successful castings of the audience I've seen as an audience member was a show called Office Party (see Cramer, 2008), in which we were all given sticky labels with a character name. I was Maureen, part of the domestic services team. The company had worked out biographies for all the characters and I was happy to play along with such statements as 'looking forward to your retirement Maureen?' and 'it's two sugars Maureen, isn't it?'. Sometimes the silent contract can be disregarded however or deliberately ignored. I spoke to the performance artist Bobby Baker years ago, who staged a show about mental illness (her own), in her own house (see Kellaway, 2009). In the first week, there was an audience member, in a small audience of about 20, who was unbelievably aggressive to Bobby during the show. She felt particularly violated, and for a long time didn't feel the same way about her kitchen, didn't feel safe in it. Making intimate work, where the audience outnumbers you, and where the site might have a very profound personal significance can be quite dangerous for the mental health of the artist. This is why we try to make work in an ethical, supported way, in rehearsal rooms without shame, but which nurture a sense of folly and adventure, and aim to respect the equal rights of all members of the team. We hope that this spirit transfers over to the experience of the audience.

Creating these alternative worlds away from the formality of a theatre setting helps to build alternative communities. The Comedy Theatre ${ }^{2}$ in London used to have a man in a dinner jacket guarding the entrance, like a casino doorman or gentleman's club concierge. It was pretty clear what kind of clientele the management were aiming for in terms of social class. Again, a consideration of who the host is becomes critical, as are the signals that the host send out. When we were planning the first Scottish tour of Decky Does A Bronco, we started chatting to a group of children in Portree playground on the Isle of Skye. They were very interested in 
the idea of a show about kids staged on a set of swings. A 12year-old girl shouted after us as we said our goodbyes: 'Just remember it's our swing park!'. This was a revelation to me. Previously we had been planning to seal the swing park to stop non-ticket holders gaining entry. But of course, the local children were the hosts and we were the guests. It was, indeed, their swing park. So, we kept each park open, with the result that the local kids played during the show in the background, adding a real layer of poignancy as the subject matter of the play darkened. The children trained the actors in the most demanding acrobatic tricks on the swings (which they could perform with ease). They swapped the football cards which made up our programme, with one girl collecting eight cards of O'Neill, the cool boy in the gang who she clearly fancied. They learned lots of the lines, sat around for the acrobatics, ran away during some of the longer speeches. They were co-creators, even more than hosts.

Host: I guess what you are creating with your hosts are more like events than plays. They are one offs...

Guest: I do think of them as plays, in that they almost always have a strong narrative drive, but also, as what I call, intimate spectacles. The audiences can be small, and very close to the action, but the cultural, social and ethical effects can be spectacular. That could be as different as the Department of Transport suspending aviation law for three weeks to allow us to perform in the restricted zone of a working international airport, to a nine-year-old boy thinking that he was in his own live film, as he happily participated as an active audience member in my show Caledonian Road (Harrison, 2002). His reference for the event was a film location-its reality and immediacy. Or it could be a spectacular effect such as that experienced by an audience member at a show we created in the former security headquarters of the Syrian secret police in Beirut. I was chatting to him about his experience of the show and he 
seemed particularly animated about a scene in the second room we visited, 'I loved that scene-it was very special to me because the last time I was in that room I was being interrogated'. He explained to me that we had re-written his memory of that room, had redefined the space as being closer to the beautiful French colonial era sitting room that it had originally been in the nineteenth century, rather than its unpleasant repurposing in the 1990s. Art had overwritten politics. On the other hand, working in Beirut was an important part of my development because it challenged some of my aesthetic presumptions. I was very attracted to the ruined buildings of Beirut from an aesthetic point of view-full of meaning and ravaged beauty. In 2004, we staged a workshop in a hotel building which had a rooftop pool that had been planned for an opening in 1975, the first year of the civil war. It had never opened, was thick with debris and dust, but pregnant with meaning, like a hugely detailed and realised stage design. Issam Bou Khaled ${ }^{3}$, a leading Lebanese theatre maker, said to me once that he was sick of this ravaged history and said that he preferred theatres to be theatres and hospitals to be hospitals. When I staged my show Ghost Ward in the abandoned St Andrews Hospital in Bow for the Almeida in 2001, I was surprised by the anger of some of the local community who wanted it to be reopened as their hospital, not used for theatre. However, a few of them came to see the show and were deeply moved by the subject matter and commitment of the mixed community and professional cast. The anger is understandable, however.

Host: I like the film idea that the boy mentioned. I get that. It was like being a protagonist in a film. It made me feel powerful, active, involved.

Guest: It's a truism that Western culture now certainly is clearly demanding more agency, more involvement. Look at the online world: Twitter, Facebook, blogs, the human need 
to articulate an individual view. But in the hostpital this individualism is balanced by a sense of community; audience and performers sharing the subject matter in a common space full of intimacy, significance, meaning and reality.

Host: Can I get you another drink?

Guest: Let me get you one. We've swapped roles remember? We're inside the fiction. I'm your host now.

Host: Thank you very much.

\section{End}

\section{Notes}

1. I am using the term host / guest in a more practical sense than the metaphor of host / ghost employed by Mike Pearson and Cliff McLucas in Kaye (2000, p.128). Whereas their term is used more in the aesthetic sense of the ephemeral nature of performance, as opposed to the solidity and relative permanence of the site (although of course its unfolding history shifting its nature through time), I am concerned here to articulate the actual flesh and blood relationship between the keyholders of the site and the intervening artist as the keyholder's guest.

2. The Comedy Theatre on Panton Street in the West End of London. It was renamed the Harold Pinter Theatre in 2011 in honour of the late playwright.

3. Issam Bou Khaled, former director of the Beirut Theatre until it closed in 2013. He now works extensively as a film actor.

\section{References}

Bukowski, C., 2009. Barflies, adapted by B. Harrison. Grid Iron. [online] Available at:

〈http://www.gridiron.org.uk/production_type/barflies-2009/〉

[Accessed 15 March 2018].

Carter, A., 1979. The Bloody Chamber. [online] Available at: 
〈http://www.gridiron.org.uk/production_type/the-bloody-chamber/〉 [Accessed 15 March 2018].

Cramer, S., 2008. Office Party. The List. [online] Available at: 〈https://edinburghfestival.list.co.uk/article/10665-office-party/〉 [Accessed 14 August 2008].

Fisher, M., 2016. 'It's our global addiction': Scottish oil drama Crude drills down to reality, in The Guardian. [online] Available at: 〈https://www.theguardian.com/stage/2016/oct/14/its-our-globaladdiction-scottish-oil-drama-crude-drills-down-to-reality> [Accessed 14 October 2016].

Harrison, B., 1998. Gargantua. Grid Iron. [online] Available at: 〈http://www.gridiron.org.uk/production_type/96/〉 [Accessed 15 March 2018].

Harrison, B., 2001. Ghost Ward. [online] Available at: 〈http://www.benharrison.info/productions/ghost-ward/〉 [Accessed 15 March 2018].

Harrison, B., 2002. Caledonian Road. [online] Available at: 〈http://www.benharrison.info/productions/caledonian-road/〉 [Accessed 15 March 2018].

Harrison, B., 2006. Roam. [online] Available at: 〈http://www.benharrison.info/productions/roam/〉 [Accessed 15 March 2018].

Harrison, B., 2016. Crude. Grid Iron. [online] Available at: 〈http://www.gridiron.org.uk/production_type/crude/〉 [Accessed 15 March 2018].

Harrison, B. \& Grid Iron., 2005. Those Eyes, That Mouth. Grid Iron. [online] Available at:

〈http://www.gridiron.org.uk/production_type/those-eyes-thatmouth/> [Accessed 15 March 2018].

Kaye, N., 2000. Site-specific art. London: Routledge.

Kellaway, K., The Interview: Bobby Baker. The Guardian [online] Available at:

〈https://www.theguardian.com/artanddesign/2009/jun/28/bobbybaker-performance-art〉 [Accessed 28 June 2009].

Maxwell, D., 2001. Decky Does A Bronco. Grid Iron. [online] Available at: 〈http://www.gridiron.org.uk/production_type/105/〉 [Accessed 15 March 2018].

Serres, M., 1995. Angels: A modern myth. Paris: Flammarion.

\section{About the author}

BEN HARRISON has been co-artistic director of site-based theatre 
practitioners Grid Iron since 1996. He was associate director of the Almeida Theatre London from 2000-2002, director of the Dutch company Muztheater from 2004-2008, and a fellow of the National Endowment for Science, Technology and the Arts (NESTA) from 20012004. He has directed for the Edinburgh International Festival and the following theatres: National Theatre of Scotland (NTS), Traverse, Tron, Òran Mór, The Arches, Citizens. He has directed theatre companies Dogstar, Tromolo Productions and Paper Doll Militia. He also directed the show Peter Pan for 360 Entertainment (UK and US tour 2009-2015) which was seen by more than $1,000,000$ people. 